\title{
Combining Geographic Information Systems and Agent-Based Models in Archaeology: Part 2 of 3
}

\author{
Benjamin Davies $\odot$, Iza Romanowska $\odot$, Kathryn Harris, and Stefani A. Crabtree $\odot$
}

\section{ABSTRACT}

Archaeologists are using spatial data in increasingly sophisticated analyses and invoking more explicit considerations of space in their interpretations. Geographic information systems (GIS) have become standard technology for professional archaeologists in the collection and management of spatial data. Many calls have been made to develop and adapt digital geospatial technologies for interpretation and understanding past social dynamics, but this has been limited to some extent by the static nature of map-oriented GIS approaches. Here, we illustrate how coupling GIS with agent-based modeling (ABM) can assist with more dynamic explorations of past uses of space and geospatial phenomena.

Keywords: agent-based modeling, geographic information systems (GIS), simulation

Los arqueólogos están usando datos espaciales en análisis cada vez más sofisticados y tomando en cuenta consideraciones más específicas en sus interpretaciones. Los sistemas de información geográficas (SIG) se han convertido en una tecnología estándar para los arqueólogos profesionales a la hora de recolectar y gestionar datos espaciales. Muchos llamaron la atención sobre la necesidad de desarrollar y adaptar tecnologías geoespaciales digitales para la interpretación y comprensión de las dinámicas sociales del pasado pero, sin embargo, se han limitado a un enfoque SIG basado en la recreación de mapas. Aquí ilustramos como la combinación de SIG con el modelado basado en agentes (ABM) puede ayudar a desarrollar exploraciones más dinámicas sobre el uso del espacio y los fenómenos geoespaciales del pasado.

Palabras clave: modelos basados en agentes, sistemas de información geográficas (SIG), simulación

Geographic information systems (GIS) are software tools used for organizing, manipulating, analyzing, and visualizing spatial data (Conolly and Lake 2006). Once a niche element in archaeology, GIS are now among the most common applications of computing in the field, and a familiar work component in the management of historic and archaeological heritage (McCoy and Ladefoged 2009). Technological developments in the collection, storage, and retrieval of geospatial data have resulted in the steady growth of datasets available for researchers, inviting increasingly sophisticated analyses of spatial processes and phenomena (Bevan 2015; McCoy 2017).

Given its history and present ubiquity, it is no surprise that GIS in archaeology has also been a subject of recurrent critique. Developments in the management and visualization of spatial data have flourished, but archaeologists have struggled with interpretive applications or using GIS to characterize causal dynamics (Aldenderfer 2010:61; Hu 2012; Lock and Pouncett 2017). Some have suggested that broadening GIS approaches beyond strict representation would help further the goals of archaeological interpretation, while many propose adapting a more explicit modeling ethos. Verhagen (2018:21 sensu Hacıgüzeller 2012) for example, recommends an "eclecticism" in spatial approaches to encourage the study and comparison of multiple pasts. Similarly, Llobera (2012:505) argues that rather than using GIS to reconstruct past landscapes, practitioners would benefit from engaging with an "archaeology of potentials," where possible scenarios are explored and compared by way of middle-range "scaffolding models."

Dynamic simulation approaches, particularly agent-based models (ABMs), are often used as a way of dealing with "potentials" in archaeology (e.g. Cucart-Mora et al. 2018; Gravel-Miguel and Wren 2018; Riris 2018). The agents in an ABM represent individual entities in a system that act according to a set of predetermined rules. Agents can use their current state along with information gathered from their environment or from other agents to change their behavior in different contexts. The primary advantage of this kind of modeling is that it allows the user to observe the emergence of macro-level (population level) regularities through the interactions of individuals over time (Epstein 2006). 
These two approaches-GIS- and agent-based modeling-are highly complementary for engaging with an archaeology of potentials. For example, studying mapped trade routes using a GIS-based least-cost path analysis will show the difference between the "easiest" route from point A to point B and the actual route discovered in the archaeological record (e.g., Frachetti et al. 2017; White and Barber 2012). To investigate a potential trading process that might have resulted in the transport following a certain path, a simulation technique (e.g., ABM) can be employed. The "artificial" trading routes generated by the ABM can then be compared with both the actual and the "ideal" (least-cost) routes to examine how the simulated processes influence path behavior and whether they could be responsible for the observed paths (e.g. Gravel-Miguel and Wren 2018). In this example, GIS-based analysis is used to detect and describe patterns in data, while ABMs act as theoretical scaffolding to investigate processes that might have led to these patterns.

ABM and GIS are different software tools that can be used to address different kinds of questions, but they share many methodological elements that situate them under the broader umbrella of geocomputation. For example, ABMs commonly feature a gridded world of attribute-carrying "patches" which operate in much the same manner as raster-like data in GIS (and can also represent polygon-like data through rasterization). Agents themselves are attribute-carrying, (usually) zero-dimensional objects similar to point-like GIS data. A time step in an ABM, then, is like a set of rule-based calculations in GIS that produce updated values for feature attributes. From a GIS-oriented perspective, the agent-based model could be thought of as a layer, but one that is capable of drawing on raster and vector datasets and transforming both itself and the underlying data (Figure 1). The repeated use of updating to represent the passage of time is a primary difference in the usual applications of ABM and GIS methods, but the fundamental operations and relationships underlying this process are conceptually similar.

Joining the two approaches brings together the precision and spatial data standards of GIS with the explicit representation of time and individual autonomy in ABM. This combination is frequently advocated in other sectors (e.g., Alghais and Pullar 2018; Crooks and Wise 2013; Guo et al. 2008), but there are few resources for doing so within archaeological literature. This how-to article will demonstrate the integration of GIS with ABM, with the aim of improving methodological capacity for theory building in archaeology.

\section{SOME PRACTICAL CONSIDERATIONS}

In archaeology, the relationships among objects within three dimensions and through time gives us context from which our interpretations are derived. Simulating social processes within a geospatial framework is appealing, then, because of the potential to connect models to real-world entities recorded as GIS data. At the same time, focusing on a specific geographic setting or distribution of data adds additional complexity to a model and can reduce its applicability beyond the case study at hand.

In model building of any kind, there is always a trade-off between realism, generality, and precision. For example, the most common output of GIS in archaeology is maps, which are models of one or more aspects of reality. For a map, maximizing detail (precision and realism) often means limiting the area being depicted (generality) to avoid significant loss of readability. The same is true in an $A B M$ : while it is possible simulate anything, trying to simulate too many processes at once makes a model difficult to interpret and therefore less useful (Bullock 2014).

Making strategic simplifications when representing real-world phenomena can improve our understanding of key relationships in a system or process. But this leaves in question whether variables not included in the model have any substantial effect on the process being modeled. Before integrating GIS and ABM, it is worthwhile to consider whether the geographic relationships between entities are important features of the model. The following questions can help to clarify this:

- Is the research question dependent on place-specific geographic conditions? There are many questions that are not dependent on a specific spatial context, even if the processes in a specific case have geographic components. For example, a study investigating the role of spatial foresight in forager movement patterns has a geographic component but may cover a wide range of potential conditions (Wren et al. 2014). In such cases, the model may need "some" geography rather than place-specific conditions, and the geographic setting could be considered a variable where any map could be used (e.g., Ullah and Bergin 2012). Alternatively, stochastic landscape generation might be more appropriate to model different kinds of geographic conditions (see Perry and O'Sullivan 2018 for an example). Some questions, though, are not easily extricated from their geographic setting. For example, models used to explore routes of hominin dispersals out of Africa (Mithen and Reed 2002) or land use in Neolithic Mediterranean contexts (Barton et al. 2015) may be dependent on specific terrestrial and marine environments or spatially explicit biophysical processes. In such cases, it may be necessary to include placespecific geospatial information.

- Are the target outcomes partly or wholly spatial measurements? Model-based studies often aim to produce outcomes that resemble real-world targets (Godfrey-Smith 2006). In some cases, these will not have an obvious spatial definition, or they can be generalized in ordinal terms such as "more or less dense." In such instances, it may be more advantageous to model abstract processes that produce these more broadly defined categories (e.g., Crema 2014; Davies et al. 2016). But sometimes, targets are defined by more precise geospatial patterning; for example, a population gradient along a particular geographic transect (Romanowska et al. 2017) or the regional distribution of ritual site characteristics (Crabtree et al. 2017). These situations may require more detailed spatial information to be included in, or produced by, the simulation.

\section{A MOTIVATING EXAMPLE}

Imagine that our research problem is focused on understanding relationships between movement and stone artifact discard in a specific geographic context. Our GIS data might include a set of spatial points representing stone quarries and a rasterized digital elevation model of an island. Here, we present a model based on Brantingham's (2003) neutral model of procurement, in which an 


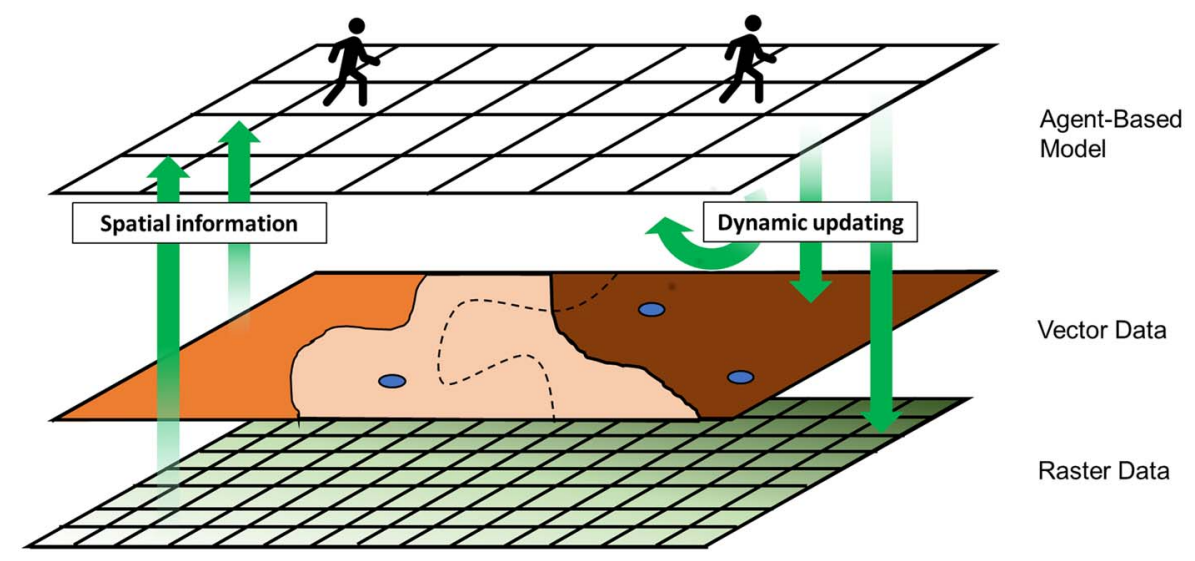

FIGURE 1. Relationships between agent-based model and integrated geographic information system.

agent moves randomly from patch to patch in the landscape and discards artefacts at each stop (Figure 2). If the agent comes into contact with a quarry, the agent fills its toolkit. In the present model, the agent makes multiple moves in places where elevation is greater than a given threshold, simulating more frequent or rapid movement at higher elevations. For the sake of the exercise, it is presumed that higher elevations would be less attractive, and that movements would therefore be more rapid, carrying the expectation that there would be less frequent discard than at lower elevations.

The example model draws on vector and raster datasets, and, in a simple way, can be used to assess how terrain might affect mobility and, by extension, frequency of discard. The interplay between the behavioral rules and the geography of the island are of interest, so values such as the number of time steps (ticks), the agents' toolkit capacity, the threshold determining "high" elevation, and a coefficient for more frequent movement applied to those higher elevations are included as tuneable model parameters with which to explore their effects on model outcomes, producing a range of potential pasts and their archaeological outcomes. Ultimately, the utility of this or any model depends on whether it sufficiently represents the theoretical historical process under examination. If not, then further elaboration of the model and its behavioral rules may be needed in order to make it work for a particular research question.

A primary barrier to the combined use of GIS and ABM in archaeology is the computational skills needed. Limited learning opportunities exist within the discipline, requiring self-teaching for many practitioners (Davies and Romanowska 2018). The remainder of this article provides an introduction on combining ABM and GIS for an archaeological study, drawing on code components from the above example. A more thorough tutorial is given as Supplemental Text, while the code and data files are available from an online repository. The average time it takes to complete the tutorial is two hours.

\section{GETTING STARTED}

There are many options for combining ABMs with GIS, including free and/or open-source options. Well-known packages used by social science researchers include Repast (North et al. 2013), NetLogo (Wilensky 1999), GAMA (Grignard et al. 2013), and Mason (Luke et al. 2005), with published comparisons available (Crooks and Castle 2012; Railsback et al. 2006). Commonly used programming languages such as Python or Java have ABM libraries that can also be made capable of interfacing with GIS data. Most of these have user communities either independently or through online forums such as Stack Exchange. Some proprietary options, such as AnyLogic, also have GIS capability and offer the added benefit of on-call technical support (Borshchev 2014). On the other end of the spectrum, ESRI software extends to the Agent Analyst package (derived from Repast), which can be used to build ABMs within the proprietary ArcGIS environment (Johnston 2013). Similarly, the Python-based MML-Lite software, developed for addressing questions related to long-term landscape ecodynamics, operates as an add-on to the popular open-source GRASS GIS software (Barton et al. 2015).

For this demonstration, NetLogo modeling software was chosen because it (a) has a built-in GIS extension; (b) can handle common spatial data types used by archaeologists (e.g., shapefiles and ASCII rasters); (c) is one of the easier ABM software packages to learn (Railsback et al. 2006); (d) has good documentation and an active user community; (e) is a stand-alone platform requiring no additional software or system configurations to operate; and $(f)$ is free to download. Although many of the principles discussed here can be transferred to other ABM platforms, the commands used herein will be specific to NetLogo. The supplemental tutorial was created using NetLogo 6.0.2, the most recent version at the time of writing, and the code can be found in a Github repository. References to NetLogo code will be printed in Courier New font. Comments, or lines of code that are not run as part of the program, are preceded by a semicolon (;) in NetLogo.

The NetLogo platform possesses several of the basic characteristics of a GIS, in the sense that it keeps track of spatial data in a systematic way, and it can be used to create visualizations of spatial data (Figure 3). The easiest way to access GIS data from NetLogo is through the GIS extension, which gives the programmer a set of commands for working with vector and raster datasets. As is done in the example model, this can be added using the following code: 


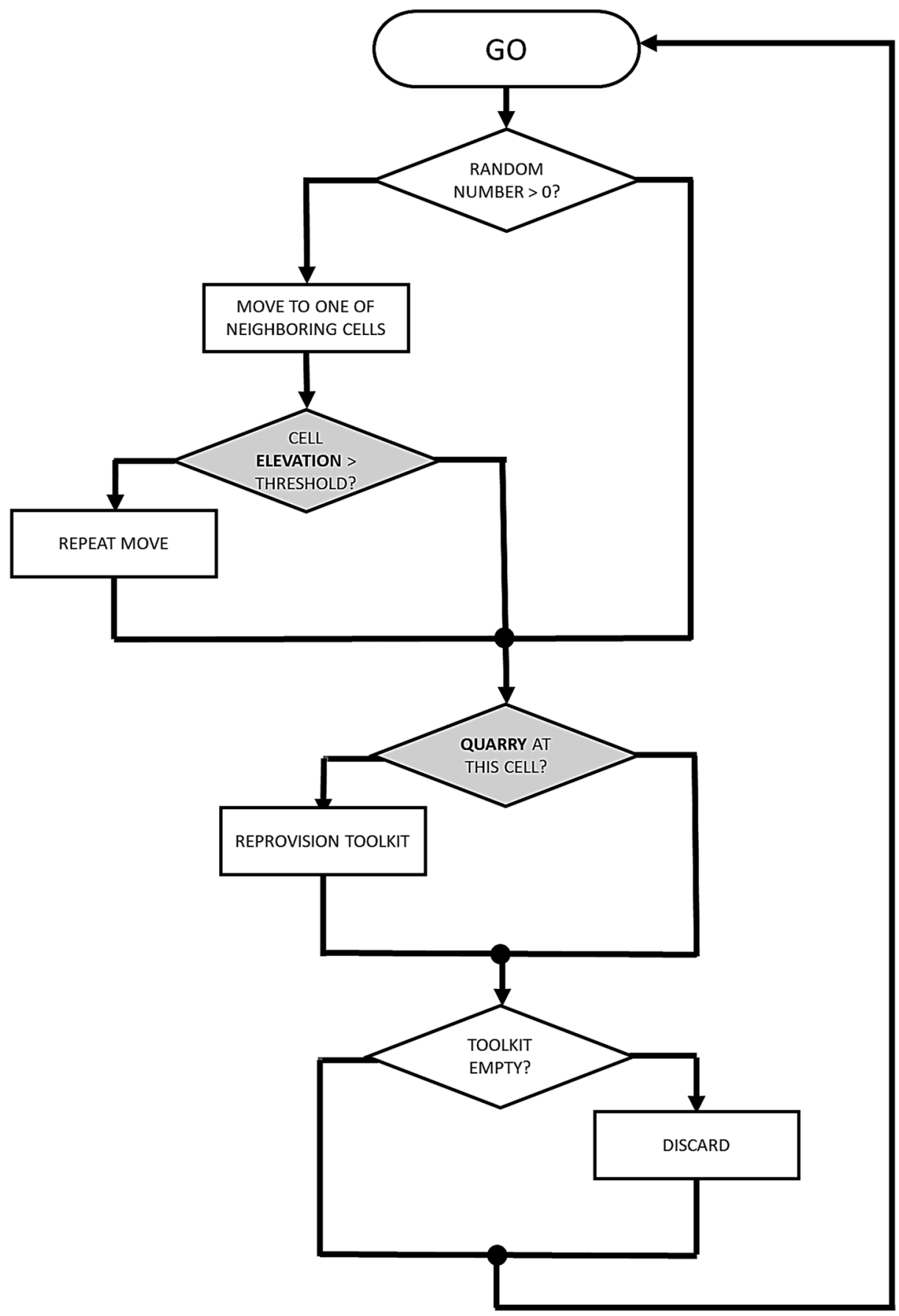

FIGURE 2. Diagram of proposed agent-based model components drawing on GIS data in shaded gray.

Example:

; access NetLogo GIS extension

extensions[ gis ]

NetLogo is similar to other ABM platforms in that it revolves around computational agents (known by the default name "turtles") following a set of behavioural rules in an environment of gridded cells (known by the default name "patches"). Both agents and grid cells can possess characteristics (turtle-owned and patch-owned variables, e.g., age, wealth, presence/absence of resources) that may change over time, typically through interactions among agents, among grid cells, and between agents and grid cells. The NetLogo user interface is divided into Interface, Info, and Code tabs, which are used for interacting, documenting, and programming, respectively. For the sake of space (pun intended), NetLogo programming basics will not be discussed in 


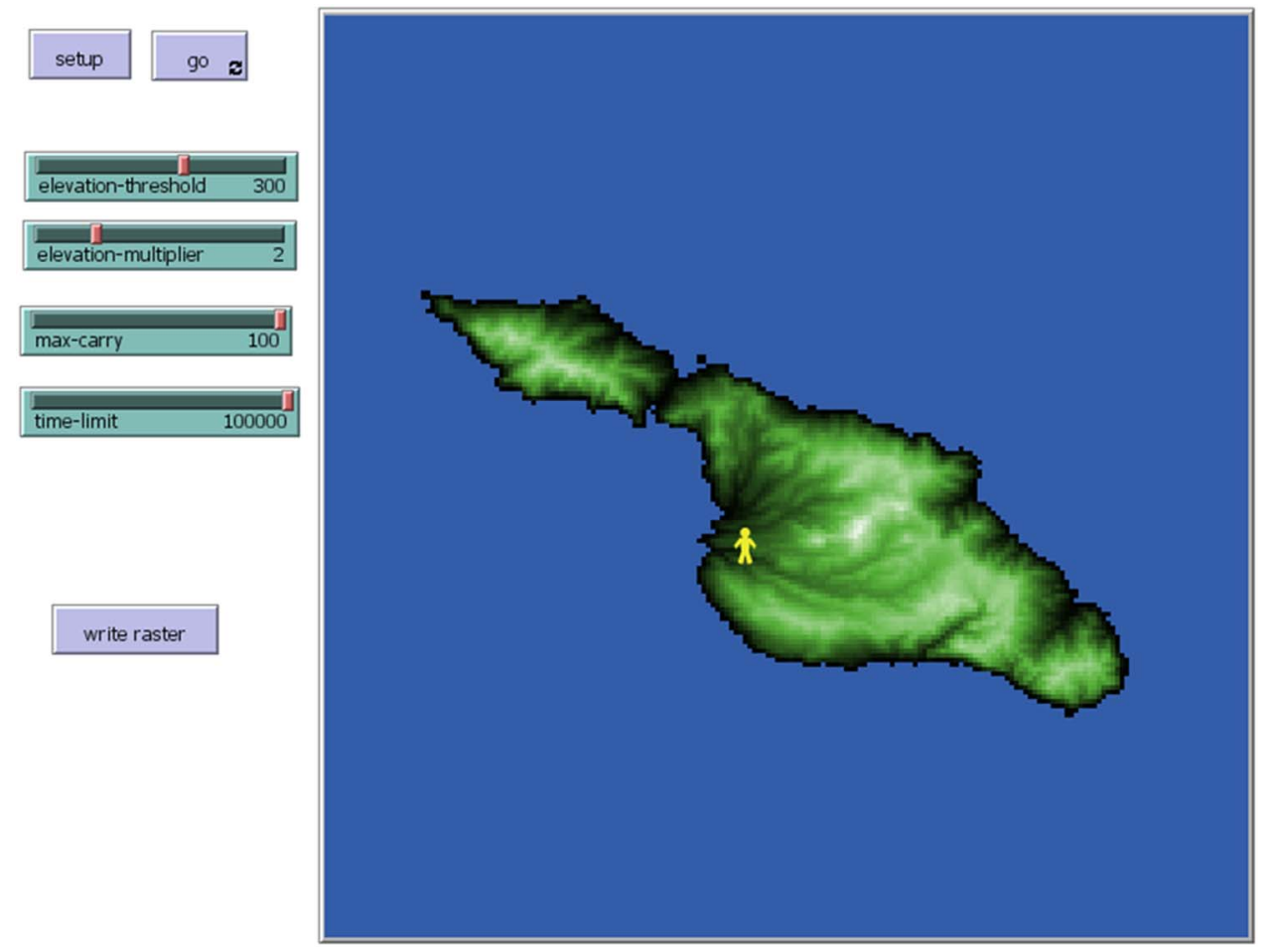

FIGURE 3. NetLogo model interface featuring imported elevation data (see supplemental tutorial for details).

any detail. Romanowska et al. (2019) provide an archaeologyspecific introduction, and there are a number of textbooks (O'Sullivan and Perry 2013; Railsback and Grimm 2012) and online tutorials that deal with NetLogo programming directly.

\section{GIS DATASET AND COORDINATE SYSTEM OPERATIONS}

In order for NetLogo to use external GIS data, the data must be loaded and interpreted in terms of the NetLogo world, including the coordinate system being used to describe the data. First, GIS data used in NetLogo need to be imported to a named variable in the NetLogo world. This is accomplished using the gis:loaddataset command, which opens a filename specified as a string. Within the example code, both the elevation dataset (raster) and the quarries (point shapefile) are loaded using this command:

\section{Example:}

; load elevation data from ascii raster

set elevation gis:load-dataset "dem.asc"

; load lithic source data from point shapefile

set quarries gis:load-dataset "quarries.shp"

Next, the extents, or "envelopes," of the GIS data need to be described in terms of the NetLogo world window. The gis: envelope-of command extracts the extent of a saved GIS dataset as a list of minimum and maximum $x$ and $y$ values, while the gis: world-envelope command does the same for the NetLogo patch world. The gis:set-world-envelope and gis:set-world-envelope-ds commands map the extent of a GIS dataset onto the NetLogo patch world, the latter permitting different scales on the $x$ and $y$ axes. The elevation dataset is used to define the world envelope in the example model:

\section{Example:}

; resize the world to fit the patch-elevation data gis: set-world-envelope gis:envelope-of elevation

Geographic coordinate systems can be used in NetLogo using the gis:load-coordinate-system command, and the coordinate system can be changed using gis:set-coordinate-system. To use gis: load-coordinate-system, geographic or projected coordinate systems in Well-Known Text (WKT) format need to be saved as .prj files in the same location as the GIS dataset being used (and, by default, this should be wherever the model's .nlogo file is saved). If a .prj file is associated with a data file, NetLogo will default to using that file and will continue to use that coordinate system for subsequent data unless otherwise specified. Alternatively, gis: set-coordinate-system can be used by converting WKT descriptions into NetLogo lists. A list of supported projected coordinate systems can be found in the NetLogo User Manual. Once again, this is drawn from the elevation data:

Example:

; loads coordinate system using the .prj file from the ; elevation 
; data

gis: load-coordinate-system "dem.prj"

\section{INTERACTING WITH GIS DATA}

There are two ways to make imported spatial data available to agents in NetLogo: by using GIS data to create or alter entities within the NetLogo world (i.e., agents or patches), or by using the GIS extension within agent or patch behavioral rules. Shapefiles are imported into NetLogo as a set of nested lists that contain the individual features within the dataset, each of their properties, their spatial locations, etc. Agents and patches can interact with these data through a set of commands that allow the user to establish whether a topological relationship holds between two entities (e.g., vector features, patches, turtles). The gis:intersects? command reports true if any part of one entity overlaps with another, while gis:contained-by? and gis:contains? only report true if the entirety of one entity is inside the bounds of another. In the example, this is used by agents who reprovision their toolkits when in proximity of a quarry:

Example:

; if a turtle shares an intersecting relationship

; with the shapefile dataset, it proceeds to the

; "reprovision-toolkit" procedure

ask turtles [

if gis:intersects? quarries self [

reprovision-toolkit

]

]

Another set of commands is used for accessing aspects of the GIS data such as vertices, features, properties (attributes), centroids, and locations. The gis:vertex-list-of and gis:feature-list-of commands return a nested list of vertices or feature properties, respectively, of a GIS dataset. When given a single feature and a property name, the gis:property-value command will give the property value for that feature (for example, the ID of a polygon). The gis:centroid-of returns $x$ and $y$ coordinates for the geographic center of a feature in GIS space, while gis:location-of gives the NetLogo location of a GIS point (or vertex or centroid). The example model uses these when the agent is reprovisioning, identifying the ID number of the nearest quarry, which will be used to associate items added to the toolkit with that quarry:

Example:

; stores the ID of a nearby quarry (the "first" ID value ; of a list of features contained by the patch where ; the turtle is located) as a temporary variable $t$ ; located) as a temporary variable $t$

let $\mathrm{gis}$ :property-value first (filter [ q $\rightarrow$ gis: contained-by? q patch-here] (gis:feature-list-of quarries)) "ID"
There are two different commands that can be used to translate a raster dataset into a NetLogo variable. The gis:raster-sample command transmits a single value from the raster at a given point, while gis:apply-raster applies the raster values to patches across the NetLogo world. In the example model, the patches sample values from the underlying raster in order to determine their own elevation:

Example:

; each patch sets its "patch-elevation" variable to

; a value extracted from the "elevation" GIS dataset

; at the patch's centroid

ask patches [

set patch-elevation gis:raster-sample elevation self

]

There are additional commands in the NetLogo GIS extension that, for the sake of space, are not covered in this brief overview. These include commands used to find maximum and minimum values of a GIS dataset, subsetting GIS features with specific values, exporting NetLogo agents as shapefiles, etc. A full list of commands can be found in the Extensions section of the NetLogo Manual. Another extension allows NetLogo to be interfaced with the R statistical computing platform (Thiele and Grimm 2010), which has packages that can be used to perform many common techniques in spatial analysis, as well as some more rarefied ones (Bivand et al. 2013).

\section{AVOIDING COMMON ERRORS}

As with all software, user errors can cause problems with both NetLogo and the GIS extension. This can be frustrating for beginning users, as the cause of error messages may be unclear. For example:

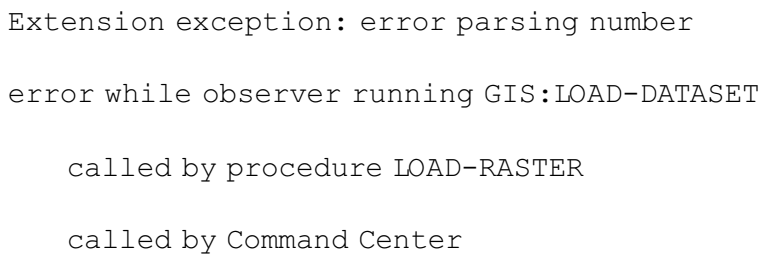

This indicates that a symbol in a GIS dataset cannot be read by NetLogo. To avoid this error, raster data used in NetLogo should be in ASCII (.asc) or ESRI grid (.grd) file types, and vector data should be ESRI shapefiles (.shp). In addition, commas should not be used in numerical values, header terms in raster files need to be separated from their values by single spaces, and files should be free from word-processor formatting such as indents and carriage returns. Many of these issues can be fixed by opening the file with a basic text editor and making the necessary changes using a search-and-replace function.

Errors also occur when simulations exceed the heap space, the memory available for objects and calculations. This can be 
changed to handle larger projects (see NetLogo Manual FAQ), but it is limited by the RAM available on the machine. It may be more appropriate in these cases to resize or resample the spatial data as long as this does not adversely affect the spatial relationships in the model or limit the size of the NetLogo world window (described in Supplemental Text).

This is by no means an exhaustive list of potential errors or solutions. If an error occurs that is not listed above, the NetLogo Users Group is a useful place to ask questions.

\section{CONCLUDING THOUGHTS}

This brief demonstration provides a basic overview for integrating GIS and ABM, but does so without providing more basic information about coding in NetLogo. The tutorials in this series, as well as those in the NetLogo User Manual, are a good place to start. Further instruction with model exemplars can be found in Wilensky and Rand (2015), O'Sullivan and Perry (2013), and Railsback and Grimm (2012).

As noted above, NetLogo is not the only software solution for integrating GIS and $A B M$, and users may find other solutions more suited to their needs. Different options vary to some extent both in their capabilities and in terms of their online documentation and tutorials. Table 1 gives a selection of platforms for which documentation was easily located at the time of publication.

The context of archaeological data is primarily spatial, and spatial relationships continue to play an important role in archaeological interpretation. As spatial data collected by archaeologists and others continues to expand and become more accessible, opportunities to draw on these datasets to evaluate and reevaulate our understanding of the past are multiplying (Bevan 2015). At the same time, a great deal of uncertainty remains around historical processes that could have given rise to archaeological patterning, spatial or otherwise. Considering material records in terms of an archaeology of potentials, one in which the archaeological record of the present is the emergent outcome of historically and geographically contingent processes, will aid in characterizing that uncertainty. Such an approach benefits from the affordances of an eclectic range of geocomputational methods (Verhagen 2018). Combining GIS and ABM offers

TABLE 1. Software Platforms and Links to Documentation for Integrating GIS and ABM

\begin{tabular}{|c|c|}
\hline Software & Documentation \\
\hline AnyLogic & $\begin{array}{l}\text { http://help.anylogic.com/topic/com.anylogic.help/ } \\
\text { html/gis/GIS\%20Architecture.html }\end{array}$ \\
\hline ESRI ArcGIS & $\begin{array}{l}\text { http://resources.arcgis.com/en/help/agent-analyst/ } \\
\text { pdf/AgentAnalyst.pdf }\end{array}$ \\
\hline GAMA & https://gama-platform.github.io/wiki/Tutorials \\
\hline Mason & $\begin{array}{l}\text { https://cs.gmu.edu/ eclab/projects/mason/ } \\
\text { extensions/geomason/ }\end{array}$ \\
\hline NetLogo & http://ccl.northwestern.edu/netlogo/docs/gis.html \\
\hline Repast & $\begin{array}{l}\text { http://repast.sourceforge.net/repast_3/how-to/ } \\
\text { Gis_How_To.html }\end{array}$ \\
\hline
\end{tabular}

archaeologists working in both academic and professional spheres a toolkit for investigating spatial processes that contribute to the dynamics of potential pasts and their material residues in the present.

\section{Supplemental Material}

For supplemental material accompanying this article, visit https:// doi.org/10.1017/aap.2019.5

Supplemental Text. Tutorial 2: Combining Geographic Information Systems and Agent-Based Models in Archaeology

\section{Acknowledgements}

This manuscript and tutorial have evolved out of a number of ABM workshops courses we have given, and we extend our thanks to the many participants who have helped us to develop these materials over the years. The authors declare no conflicts of interest. IR received funding from the European Research Council (ERC) under the European Union's Horizon 2020 Research and Innovation programme (grant agreement no.

ERC-2013-ADG340828). SC acknowledges support by NSF Graduate Research Fellowship DGE-080667, an NSF GROW fellowship, and a Chateaubriand Fellowship. BD acknowledges support as a postdoctoral fellow from NSF under CNHS-1826666. We thank three anonymous reviewers for comments that benefited the manuscript. We also thank Colin Wren for providing detailed consideration of the manuscript and tutorial materials.

\section{Data Availability Statement}

Software used in the tutorial is open access and open source. Code and data files are available from a Zenodo repository. The "dem.asc" dataset used in this example is an ASCII raster extracted from tile n34w119 of the USGS National Elevation Dataset, centered on Santa Catalina Island, California. The "quarries.shp" dataset is a shapefile of simulated quarry locations.

\section{REFERENCES CITED}

Aldenderfer, Mark

2010 Seeing and Knowing: On the Convergence of Archaeological Simulation and Visualization. In Simulating Change: Archaeology into the Twenty-First Century, edited by Andre Costopoulos and Mark Lake, pp. 53-68. University of Utah Press, Salt Lake City.

Alghais, Nayef, and David Pullar

2018 Modelling Future Impacts of Urban Development in Kuwait with the Use of ABM and GIS. Transactions in GIS 22(1):20-42. DOI:10.1111/tgis.12293.

Barton, C., Isaac Ullah, Arjun Heimsath, C. Michael Barton, Isaac Ullah, and Arjun Heimsath

2015 How to Make a Barranco: Modeling Erosion and Land-Use in Mediterranean Landscapes. Land 4(3):578-606. DOI:10.3390/land4030578. Bevan, Andrew

2015 The Data Deluge. Antiquity 89(348):1473-1484

Bivand, Roger S., Edzer J. Pebesma, and Virgilio Gomez-Rubio

2013 Applied Spatial Data Analysis with R (Use R!). 2nd ed. Springer, New York. Borshchev, Andrei

2014 Multi-Method Modelling: AnyLogic. In Discrete-Event Simulation and System Dynamics for Management Decision Making, edited by Sally Brailsford, Leonid Churilov, and Brian Dangerfield. Wiley Online Books. DOI:10.1002/9781118762745.ch12. 
Brantingham, P. Jeffrey

2003 A Neutral Model of Stone Raw Material Procurement. American Anthropologist 68(3):487-509. DOI:10.2307/3557105

Bullock, Seth

2014 Levins and the Lure of Artificial Worlds. The Monist 97(3):301-320 DOI:10.5840/monist201497320

Conolly, James, and Mark Lake

2006 Geographical Information Systems in Archaeology. Cambridge University Press, Cambridge.

Crabtree, Stefani A., R. Kyle Bocinsky, Paul L. Hooper, Susan C. Ryan, and Timothy A. Kohler

2017 How to Make a Polity (in the Central Mesa Verde Region). American Antiquity 82(1):71-95. DOI:10.1017/aaq.2016.18.

Crema, Enrico R

2014 A Simulation Model of Fission-Fusion Dynamics and Long-Term Settlement Change. Journal of Archaeological Method and Theory 21 (2):385-404. DOI:10.1007/s10816-013-9185-4.

Crooks, Andrew T., and Christian J. E. Castle

2012 The Integration of Agent-Based Modelling and Geographical Information for Geospatial Simulation. In Agent-Based Models of Geographical Systems, edited by Alison J. Heppenstall, Andrew T. Crooks, Linda M. See, and Michael Batty, pp. 219-251. Springer, Dordrecht, Netherlands.

Crooks, Andrew T., and Sarah Wise

2013 GIS and Agent-Based Models for Humanitarian Assistance. Computers, Environment, and Urban Systems 41:100-111. DOI:10.1016/ j.compenvurbsys.2013.05.003.

Cucart-Mora, Carolina, Sergi Lozano, and Javier Fernández-López de Pablo 2018 Bio-Cultural Interactions and Demography during the Middle to Upper Palaeolithic Transition in Iberia: An Agent-Based Modelling Approach. Journal of Archaeological Science 89:14-24. DOI:10.1016/j.jas.2017.11.001.

Davies, Benjamin, Simon J. Holdaway, and Patricia C. Fanning

2016 Modelling the Palimpsest: An Exploratory Agent-Based Model of Surface Archaeological Deposit Formation in a Fluvial Arid Australian landscape. The Holocene 26(3):450-463. DOI:10.1177/0959683615609754.

Davies, Benjamin, and Iza Romanowska

2018 An Emergent Community? Agent-Based Modelers in Archaeology. SAA Archaeological Record 18(1):27-32.

Epstein, Joshua M

2006 Generative Social Science: Studies in Agent-Based Computational Modeling. Princeton Studies in Complexity. Princeton University Press, Princeton, New Jersey.

Frachetti, Michael D., C. Evan Smith, Cynthia M. Traub, and Tim Williams

2017 Nomadic Ecology Shaped the Highland Geography of Asia's Silk Roads. Nature 543(7644):193-198. DOI:10.1038/nature21696.

Godfrey-Smith, Peter

2006 The Strategy of Model-Based Science. Biological Philosophy 21:725-740.

Gravel-Miguel, Claudine, and Colin D. Wren

2018 Agent-Based Least-cost Path Analysis and the Diffusion of Cantabrian Lower Magdalenian Engraved Scapulae. Journal of Archaeological Science 99:1-9. DOI:10.1016/j.jas.2018.08.014.

Grignard, Arnaud, Patrick Taillandier, Benoit Gaudou, Duc An Vo, Nghi Quang Huynh, and Alexis Drogoul

2013 GAMA 1.6: Advancing the Art of Complex Agent-Based Modeling and Simulation. In PRIMA 2013: Principles and Practice of Multi-Agent Systems, pp. 117-131. Lecture Notes in Computer Science. Springer, Berlin.

Guo, Dan, Bo Ren, and Cheng Wang

2008 Integrated Agent-Based Modeling with GIS for Large-Scale Emergency Simulation. In Advances in Computation and Intelligence, edited by Lishan Kang, Zhihua Cai, Xuesong Yan, and Yong Liu, pp. 618-625. Lecture Notes in Computer Science. Springer, Berlin Heidelberg.

Hacıgüzeller, Piraye

2012 GIS, Critique, Representation, and Beyond. Journal of Social Archaeology 12(2):245-263. DOI:10.1177/1469605312439139.

$\mathrm{Hu}, \mathrm{Di}$

2012 Advancing Theory? Landscape Archaeology and Geographical Information Systems. Papers from the Institute of Archaeology 21:80-90 DOI:10.5334/pia.381.
Johnston, Kevin M

2013 Agent Analyst: Agent-Based Modeling in ArcGIS. ESRI, Redlands, California.

Llobera, Marcos

2012 Life on a Pixel: Challenges in the Development of Digital Methods within an "Interpretive" Landscape Archaeology Framework. Journal of Archaeological Method and Theory 19(4):495-509. DOI:10.1007/ s10816-012-9139-2.

Lock, Gary, and John Pouncett

2017 Spatial Thinking in Archaeology: Is GIS the Answer? Journal of Archaeological Science 84:129-135. DOI:10.1016/j.jas.2017.06.002.

Luke, Sean, Claudio Cioffi-Revilla, Liviu Panait, Keith Sullivan, and Gabriel Balan 2005 MASON: A Multiagent Simulation Environment. SIMULATION 81(7):517527. DOI:10.1177/0037549705058073.

McCoy, Mark D.

2017 Geospatial Big Data and Archaeology: Prospects and Problems Too Great to Ignore. Journal of Archaeological Science 84:74-94. DOI:10.1016/ j.jas.2017.06.003.

McCoy, Mark D., and Thegn N. Ladefoged

2009 New Developments in the Use of Spatial Technology in Archaeology. Journal of Archaeological Research 17(3):263-295. DOI:10.1007/ S10814-009-9030-1.

Mithen, Steven, and Melissa Reed

2002 Stepping Out: A Computer Simulation of Hominid Dispersal from Africa. Journal of Human Evolution 43:433-462.

North, Michael J., Nicholson T. Collier, Jonathan Ozik, Eric R. Tatara, Charles M. Macal, Mark Bragen, and Pam Sydelko

2013 Complex Adaptive Systems Modeling with Repast Simphony. Complex Adaptive Systems Modeling 1(1):3. DOI:10.1186/2194-3206-1-3.

O'Sullivan, David, and George L. W. Perry

2013 Spatial Simulation: Exploring Pattern and Process, Wiley, West Sussex.

Perry, George L. W., and David O'Sullivan

2018 Identifying Narrative Descriptions in Agent-Based Models Representing Past Human-Environment Interactions. Journal of Archaeological Method and Theory 25(3):795-817. DOI:10.1007/s10816-017-9355-x.

Railsback, Steven F., and V. Grimm

2012 Agent-Based and Individual-Based Modeling: A Practical Introduction, Princeton University Press, Princeton, New Jersey.

Railsback, Steven F., Steven L. Lytinen, and Stephen K. Jackson

2006 Agent-Based Simulation Platforms: Review and Development Recommendations. Simulation 82(9):609-623. DOI:10.1177/0037549706073695. Riris, Philip

2018 Assessing the Impact and Legacy of Swidden Farming in Neotropical Interfluvial Environments through Exploratory Modelling of Post-Contact Piaroa Land Use (Upper Orinoco, Venezuela). The Holocene 28(6):945-954. DOI:10.1177/0959683617752857

Romanowska, Iza, Clive Gamble, Seth Bullock, and Fraser Sturt

2017 Dispersal and the Movius Line: Testing the Effect of Dispersal on Population Density through Simulation. Quaternary International 431:53-63. DOI:10.1016/j.quaint.2016.01.016.

Romanowska, Iza, Stefani Crabtree, Kathryn Harris, and Benjamin Davies.

2019 Agent-Based Modeling for Archaeologists: Part 1 of 3. Advances in Archaeological Practice 7:178-184. DOI:10.1017/aap.2019.6

Thiele, Johannes C., and Volker Grimm

2010 NetLogo meets R: Linking Agent-Based Models with a Toolbox for Their Analysis. Environmental Modelling \& Software 25(8):972-974. DOI:10.1016/ j.envsoft.2010.02.008.

Ullah, Isaac T., and Sean M. Bergin

2012 Modeling the Consequences of Village Site Location: Least Cost Path Modeling in a Coupled GIS and Agent-Based Model of Village Agropastoralism in Eastern Spain. In Least Cost Analysis of Social Landscapes: Archaeological Case Studies, edited by Devin A. White and Sarah L. Surface-Evans, pp. 155-173. University of Utah Press, Salt Lake City.

Verhagen, Philip

2018 Spatial Analysis in Archaeology: Moving into New Territories. In Digital Geoarchaeology: New Techniques for Interdisciplinary Human-Environmental Research, edited by Christopher Siart, 
HOW-TO SPECIAL SECTION

Markus Forbriger, and Olaf Bubenzer, pp. 11-25. Springer International, Cham, Switzerland.

White, Devin A., and Sarah B. Barber

2012 Geospatial Modeling of Pedestrian Transportation Networks: A Case Study from Precolumbian Oaxaca, Mexico. Journal of Archaeological Science 39(8):2684-2696. DOI:10.1016/j.jas.2012.04.017.

Wilensky, Uri

1999 NetLogo 5.0.4. Center for Connected Learning and Computer-Based Modeling, Northwestern University, Evanston, Illinois, (http://ccl.northwestern.edu/netlogo).

Wilensky, Uri, and William Rand

2015 An Introduction to Agent-Based Modeling: Modeling Natural, Social, and Engineered Complex Systems with NetLogo. MIT Press, Cambridge, Massachusetts.

Wren, Colin D., Julian Z. Xue, Andre Costopoulos, and Ariane Burke

2014 The Role of Spatial Foresight in Models of Hominin Dispersal. Journal of Human Evolution 69:70-78. DOI:10.1016/j.jhevol.2014.02.004.

\section{AUTHOR INFORMATION}

Benjamin Davies Department of Anthropology, University of Utah, $260 \mathrm{~S}$ Central Campus Drive, Room 4625, Salt Lake City, UT 84112, USA (ben.davies@ utah.edu, corresponding author) https://orcid.org/0000-0002-9066-098X

Iza Romanowska Barcelona Supercomputing Center, Carrer de Jordi Girona, 29-31, 08034 Barcelona, Spain (iza.romanowska@bsc.es) https://orcid.org/ 0000-0002-9487-2111

Kathryn Harris Science \& Technology Policy Fellow, The American Association for the Advancement of Science and The American Geophysical Union, 2000 Florida Avenue NW, Washington, DC 20009, USA (kaharris@wsu. edu)

Stefani A. Crabtree - Utah State University Department of Environment and Society, 5200 Old Main Hill, Logan, UT 84322, USA; The Santa Fe Institute, 1399 Hyde Park Rd. Santa Fe, NM, USA; The Center for Research and Interdisciplinarity, 8 bis Rue Charles V Paris 75004, France (sac376@psu.edu) https://orcid.org/0000-0001-8585-8943 